\title{
Depletion of GPSM1 enhances ovarian granulosa cell apoptosis via cAMP-PKA- CREB pathway in vitro
}

\author{
Xuzi Cai, Huijiao Fu, Yan Wang, Qiwen Liu and Xuefeng Wang ${ }^{*}$ (1)
}

\begin{abstract}
Background: Genetic causes of premature ovarian insufficiency (POI) account for approximately $20 \sim 25 \%$ of patients. So far, only a few genes have been identified.

Results: Here, we first identified the c.1840C > A on G-protein signaling modulator 1 (GPSM1) as a susceptibility locus for POI in 10 sporadic POI patients by whole-exome sequencing. The frequency of GPSM1 c.1840C > A was then verified as 3/20 in a POI sample of 20 patients (including the above 10 patients) by Sanger sequencing. RTPCR and western blot analysis showed the expression of GPSM1 in rat ovaries was increased in the large antral follicle stage compared to the primordial follicle stage $(P<0.01)$. The cell proliferation assay (CCK8) and flow cytometry suggested that the small-interfering RNA-induced silencing of Gpsm1 significantly increased apoptosis and decreased proliferation of rat ovarian granulosa cells (GCs) $(P<0.01)$. Furthermore, suppression of Gpsm1 in GCs reduced levels of CAMP, PKAc, p-CREB as well as the ratio of Bcl-2/Bax, and increased the expression of Caspase-3 and Cleaved Caspase-3 $(P<0.01)$.
\end{abstract}

Conclusions: In summary, this study identified a susceptibility variant GPSM1 c.1840C > A of POI for the first time. Gpsm1 was related to rat follicle development, and silencing of Gpsm 1 increased apoptosis and decreased proliferation in rat GCs, possibly through inhibition of the CAMP-PKA-CREB pathway.

Keywords: Premature ovarian insufficiency, Whole-exome sequencing, GPSM1, Ovarian granulosa cell, cAMP-PKACREB pathway

\section{Introduction}

Premature ovarian insufficiency (POI) is a clinical syndrome characterized by the loss of ovarian activity before the age of 40 years, which results in hypergonadotropic hypogonadism [1]. It affects approximately $1 \%$ women under 40 years old [2]. The opportunity to preserve fertility in women with POI is poor, which has a negative impact on both the psychological and reproductive health of women of childbearing age. As women are marrying at a later age, infertility caused by POI is becoming a greater

\footnotetext{
* Correspondence: douwangxuefeng@163.com

Department of Obstetrics and Gynecology, The Third Affiliated Hospital of Southern Medical University, No. 183 West Zhongshan Avenue, Guangzhou 510000, Guangdong, China
}

concern. Early detection of the high-risk population would allow for increased treatment options, and perhaps the POI-related infertility could be avoided. Research into the pathogenesis of POI is particularly important for molecular diagnosis and prevention.

Although most POI cases are idiopathic, genetic factors are considered to be one of the main causes of POI [3], accounting for $20-25 \%$ [4]. Currently, only several genes have been confirmed to be associated with the pathogenesis of POI, including FOXL2, BMP2, NOBOX, FIGLA, and GDF9 [5]. The screening and validation of POI candidate genes is a large task. Currently, most of the research on POI-pathogenesis genes is focused on pedigree studies [6, 7]. However, POI presents with high

(c) The Author(s). 2020 Open Access This article is licensed under a Creative Commons Attribution 4.0 International License, which permits use, sharing, adaptation, distribution and reproduction in any medium or format, as long as you give appropriate credit to the original author(s) and the source, provide a link to the Creative Commons licence, and indicate if changes were made. The images or other third party material in this article are included in the article's Creative Commons licence, unless indicated otherwise in a credit line to the material. If material is not included in the article's Creative Commons licence and your intended use is not permitted by statutory regulation or exceeds the permitted use, you will need to obtain permission directly from the copyright holder. To view a copy of this licence, visit http://creativecommons.org/licenses/by/4.0/ The Creative Commons Public Domain Dedication waiver (http://creativecommons.org/publicdomain/zero/1.0/) applies to the data made available in this article, unless otherwise stated in a credit line to the data. 
genetic heterogeneity; each family or individual patient seems to be unique in the pathogenesis and there is no significant definitive pathogenic gene for POI. If common pathogenic mutations can be sought out in sporadic POI populations, more insight into the genetic changes of POI patients can be gained. In recent years, with the development and maturity of high-throughput sequencing technologies, whole-exome sequencing (WES) has been widely applied to explore new pathogenic genes of hereditary disease, and has been verified as an effective tool for research into genetic etiology [8-10].

In this study, we used WES to initially identify a POI susceptibility gene in unrelated Chinese women affected by POI. A functional study in vitro was then carried out using rat ovarian granulosa cells (GCs). The outcome of this study provided an insight of the etiology of POI by providing new candidates and pathways.

\section{Results}

\section{WES and sanger sequencing identified heterozygous} GPSM1 mutation in $3 \mathrm{POI}$ patients

We performed WES on 10 POI patients. The mean coverage of the target region is $99.8 \%$. More than $98.76 \%$ of the target was covered at $20 \times$ depth. We applied the following exome filtration procedure: total variants called in 10 patients and variants that are absent or with minor allele frequency less than $1 \%$ in the population public databases (dbSNP, 1000Genomes, and ExAC). After these filters, a total of 12 genes including 22 variants were retained: OR2T29 (c.26A > G), ANKRD36C (c.1265 T > G), FRG1 (c.330G > T), PSPH (c.268G > A), PABPC3 (c.541G > A, c.691A > G, c.832C > T, c.859A > G, c. $938 \mathrm{C}>\mathrm{T}$, c. $956 \mathrm{C}>$ T), LMO7 (c.911G > A), TPSAB1 (c.422C > T), TBC1D26 (c.167A > C), CNN2 (c.629 T > C, c.630G > A, c.632G > T, c.670G > A, c.680G > A, c.695C > A), DKKL1 (c.71 T > G), SCUBE1 (c.1169C > G), and GPSM1 (c.1840C > A). All the above mutations presented as heterozygous. Details of all variants are listed in Table 1 . Of these candidate genes, GPSM1 (G-protein signaling modulator 1) sparked our interest. For GPSM1 (c.1840C > A), the ExonicFunc. refGene, rs number, mutation frequency in ExAC, mutation frequency in $1000 \mathrm{G}($ all), SIFT score, Ployphen2 score were missense mutation, rs539775258, 0.000008446, 0.0002, 0.001, and 0.998, respectively. Protein alignments revealed the GPSM1 p. Glu614Lys variant, located in the third G-protein regulatory (GPR) motif of the protein, affected an amino acid highly conserved among species (Fig. 1). Sanger sequencing confirmed that GPSM1 (c.1840C > A) were heterozygous in $3 / 20$ patients.

\section{Increased level of GPSM1 in multi-follicle developed ovary}

Multi-follicle development in immature rats was successfully promoted. The ovaries of the PMSG group were significantly enlarged, congestive, and multifollicles developed compared to the NS group (Fig. 2a). The weight of the ovaries in the PMSG group increased significantly, about three times as much as the NS group $(P<0.01$, Fig. 2b). A significant increase in GPSM1 mRNA and protein expression was observed in the PMSG group compared to the NS group, as demonstrated by RT-PCR and western blot analysis, respectively $(P<0.01$, Fig. 2 c, d).

\section{GPSM1 downregulated affects cell apoptosis and proliferation in rat GCs}

GPSM1 was widely expressed in the rat ovaries (Fig. 3a), such as in oocytes, GCs, luteal cells, and stromal cells. Considering the significant role of GCs in follicular development, we further investigated the role of GPSM1 in GCs. Three siRNAs targeting Gpsm1 (siRNA-1, siRNA2, and siRNA-3) and a siRNA for a negative control (NC-siRNA) were designed and individually transfected into GCs. The results show that NC-siRNA had no significant effect on the expression of GPSM1, and siRNA3 had the highest knockdown efficiency $(>70 \%)$ at both mRNA and protein levels (Fig. 3b, c); siRNA-3 was used in the following experiments. The CCK8 assay showed GCs in both groups were in a proliferative trend, but Gpsm1-knockdown markedly decreased proliferation at $48 \mathrm{~h}, 72 \mathrm{~h}, 96 \mathrm{~h}$, and $120 \mathrm{~h}(P<0.01$, Fig. 3d). Flow cytometry analysis revealed that Gpsm1-knockdown significantly increased the apoptosis rate of GCs $(P<0.01$, Fig. 3e, f).

\section{Downregulating of Gpsm 1 alters the expression of the CAMP-CREB-PKA signaling molecules in GCs}

Next, we investigated the effect of Gpsm1-knockdown on intracellular signaling in rat GCs. RT-PCR revealed that the cAMP level decreased concomitantly with down-regulation of Gpsm1 $(P<0.01$, Fig. 4a). It is widely known the various effects of cAMP are achieved mainly through activation of cAMP-dependent protein kinase A (PKA). Unexpectedly, there was no significant difference in PKA mRNA expression between the two groups $(P>$ 0.05 , Fig. 4a). Therefore, we targeted PKAc, a catalytic subunit of PKA, protein levels for western blot analysis. The PKAc protein level was significantly reduced in the Gpsm1-silenced group compared to the NC group $(P<$ 0.01 , Fig. 4b). As some studies have reported that GPSM1 could regulate the phosphorylation of cAMPresponse element binding protein (CREB) by mediating PKA [11], and p-CREB could regulate transcription of the apoptosis suppressor Bcl-2 [12], the CREB, p-CREB, and $\mathrm{Bcl}-2$ protein levels were assessed. Both the RNA and protein expression of $\mathrm{p}$-CREB and Bcl-2 were attenuated in the Gpsm1-silenced group compared to the NC group $(P<0.01$, Fig. 4$)$, while CREB expression showed 


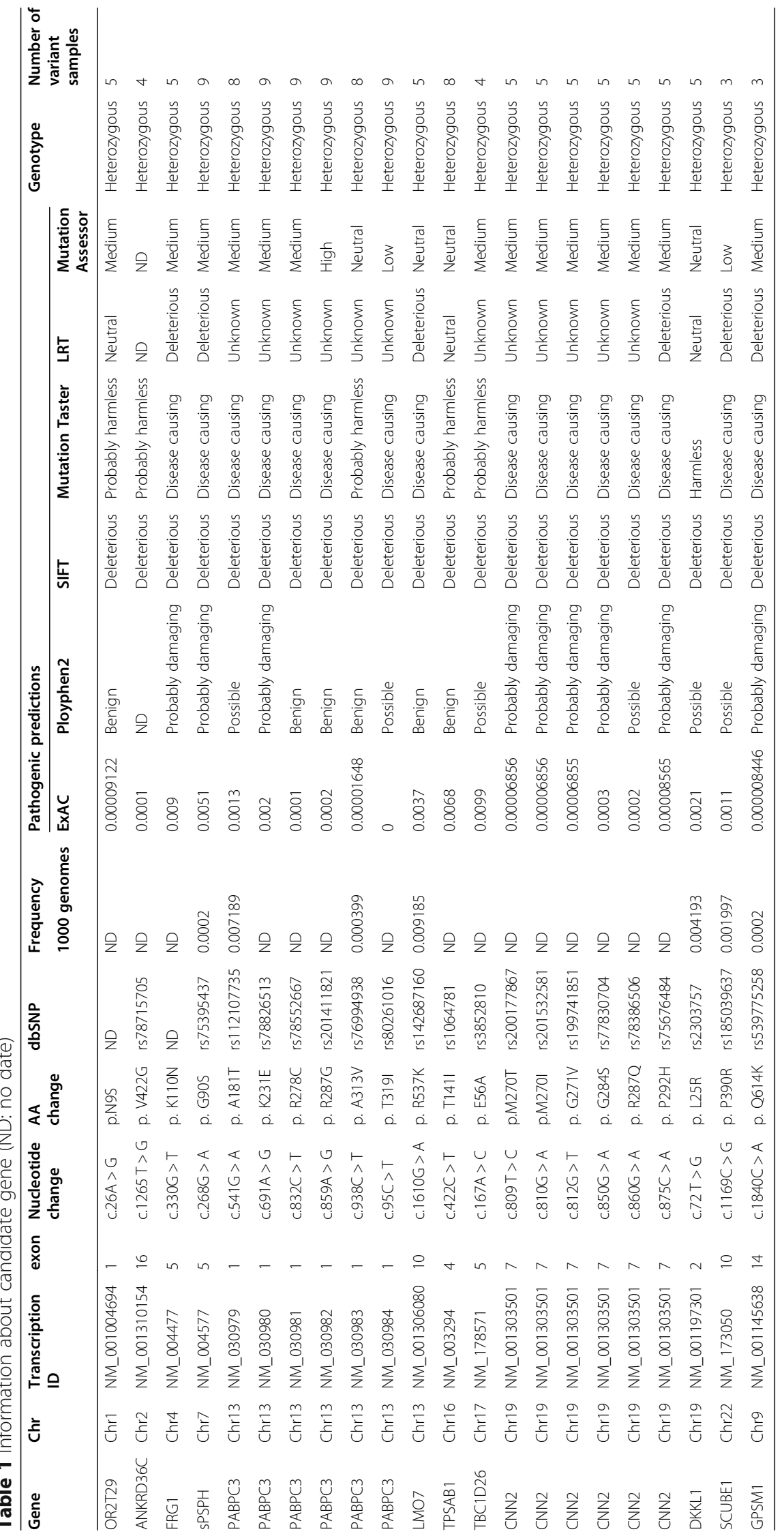




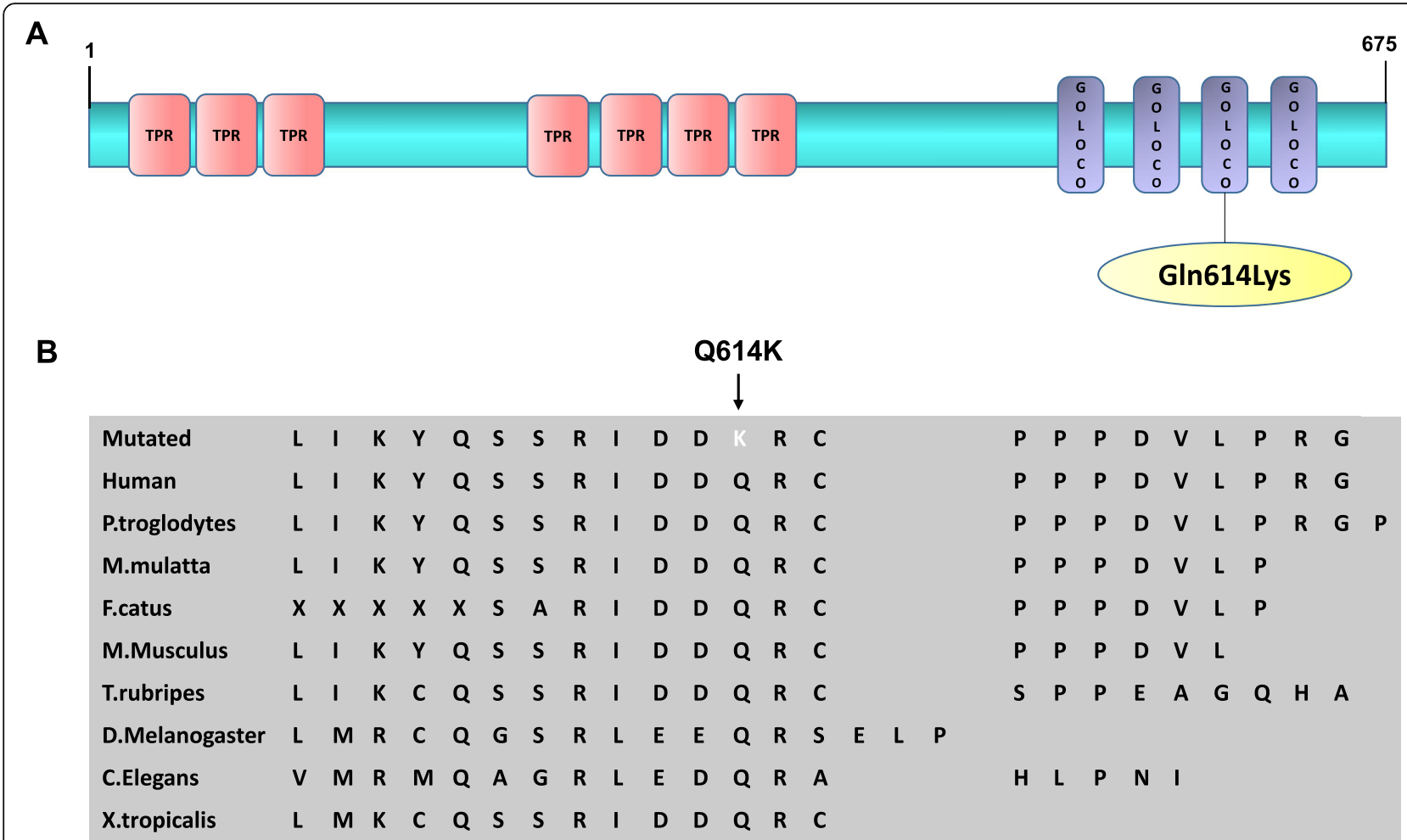

Fig. 1 Hotspot and conservation sites of GPSM1 Q614K. a. Functional domain information of Glu614Lys (Q614K) in protein GPSM1. b. Conservation analysis of GPSM1 Q614K among different species

no significant difference $(P>0.05$, Fig. 4$)$. To calculate the ratio of $\mathrm{Bcl}-2 / \mathrm{Bax}$, Bax was quantified; the results showed an elevation of $\mathrm{Bcl}-2 / \mathrm{Bax}$ on RNA levels in the Gpsm1-silenced group $(P<0.01$, Fig. $4 \mathrm{a})$ but no difference between groups at the protein level $(P>0.05$, Fig. $4 \mathrm{~b})$. However, the ratio of $\mathrm{Bcl}-2 / \mathrm{Bax}$ was noticeably decreased at both the RNA and protein levels. Finally, RNA and protein levels of Caspase-3, and protein levels of cleaved Caspase-3, were found to be elevated in the Gpsm1-silenced group ( $P<0.01$, Fig. 4$)$.

\section{Discussion}

From our study of 10 POI patients, we identified a possible POI susceptibility gene, GPSM1. The GPSM1 gene was reported in public expression databases to be expressed in multiple types of tissue and cell, especially in ovary (https://www.ncbi.nlm.nih.gov/gene/26086). It encodes activator of G protein signaling 3 (AGS3), which was identified as an evolutionarily conserved protein [13, 14] and to be associated with cell division [15], cell proliferation [16], differentiation [17], autophagy [18] and so on. AGS3 has a modular domain structure consisting of seven tetratricopeptide repeats (TPRs) and four Gprotein regulatory (GPR) motifs. It was a regulatory accessory protein of G-protein signaling which could bind preferentially to inactive $G \alpha / o$ subunit complexed with guanine dinucleotide phosphate (GDP) at multiple GPR motif repeats $[15,19,20]$. Thus, it could regulate the production of cAMP which is one of the most important second messengers in pathways of metabolism, apoptosis, proliferation and material transport. The heterozygous variant of GPSM1 c. $1840 \mathrm{C}>\mathrm{A}$ is a missense mutation occurring at the third GPR motif of ASG3, leading to a change in amino acid sequence, thus likely to be a highly pathogenic mutation. Sanger sequencing determined the frequency of GPSM1 c.1840C > A in the small POI sample of 20 patients to be $3 / 20$. This suggested GPSM1 c.1840C > A might be involved in POI. To the best of our knowledge, this is the first report of GPSM1 c.1840C > A in POI patients.

Early studies $[21,22]$ have shown that at $24 \mathrm{~h}$ following PMSG treatment, the ovaries of rats presented with multiple follicular growth, and at $48 \mathrm{~h}$, the follicular antrum was extremely large and the parietal granulosa cell layer became very thin. Here, we first explored the expression pattern of GPSM1 at different stages of ovarian growth in rats. The results showed that the expression of GPSM1 was significantly increased in the large antral follicle stage compared to the primordial follicle stage. This result indicated that GPSM1 might play an important role in follicular growth in rats. 


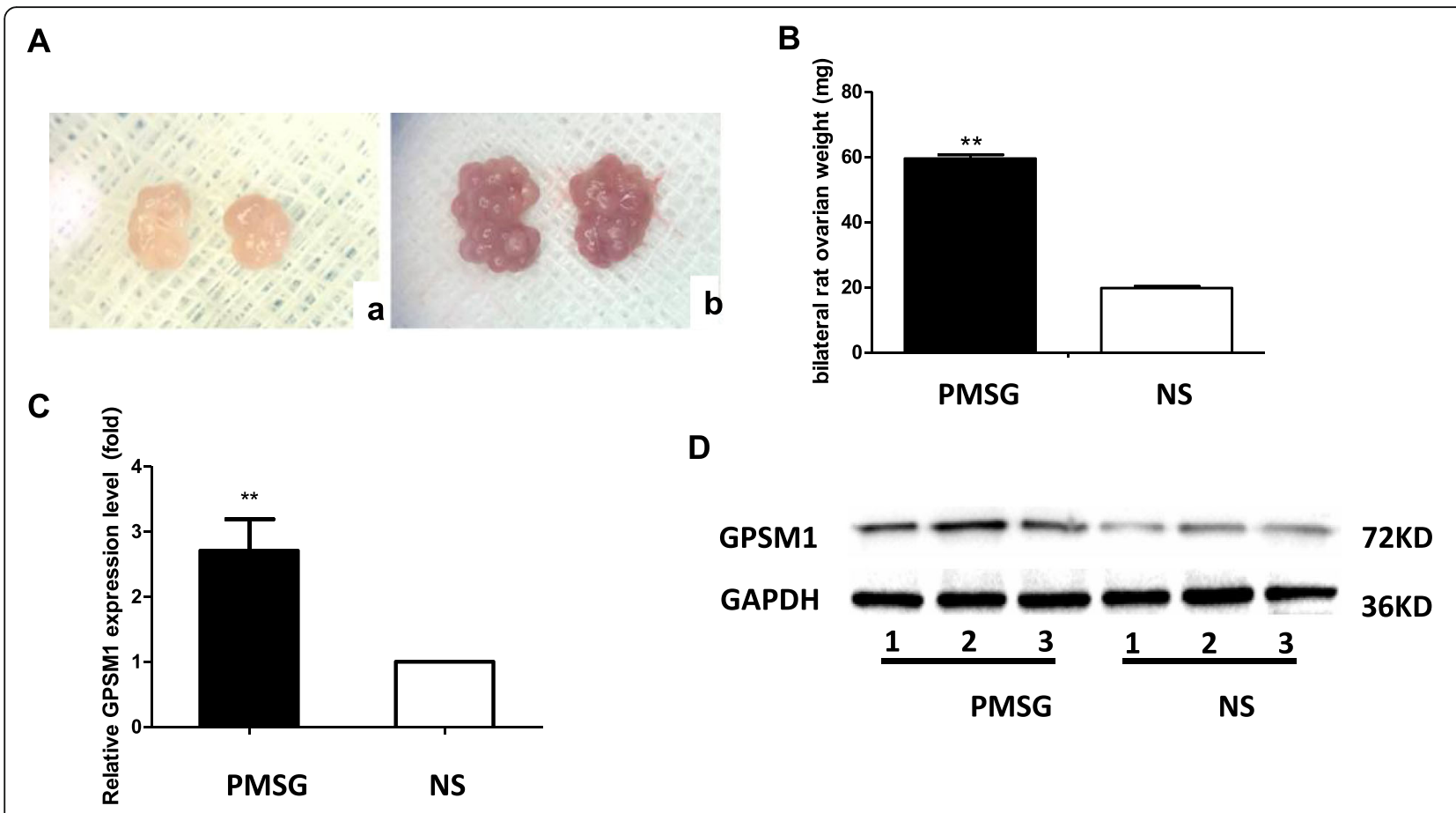

Fig. 2 The expression of GPSM1 in ovaries before and after multi-follicle development. A. Morphological changes of rat ovaries: a. Ovaries from NS-treated immature rats were light pink and normal in size; b. Ovaries from PMSG-primed immature rats were significantly enlarged, with hyperemia and mulberry-like changes. B. The weight of the bilateral rat ovaries after treatment in the experimental group (PMSG group, $n=3$ ) was significantly increased compared to the control group (NS group, $n=3)\left({ }^{* *} P<0.01\right)$. C and D. The expression of GPSM1 detected by RT-PCR and western blot was up-regulated in the PMSG group $(n=3)$ compared to the NS group $(n=3)\left(^{* *} P<0.01\right)$

The apoptosis of GCs and follicular atresia have been shown to play key roles in the pathogenesis of POI [3, 23]. The mechanism by which GPSM1 regulates heterotrimeric G-proteins in GCs has yet to be elucidated. GPSM1, encoding AGS3, could compete with free G

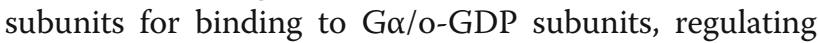
downstream signal transduction pathways by inhibiting the Gi subunit. The Gi subunit directly inhibits adenylyl cyclase (AC) activity [24]. That is how GPSM1 conducts signals, by activating $\mathrm{AC}$ to promote the synthesis of cAMP. Changes in cAMP levels are a common observation in the growth and maturation of GCs $[25,26]$. Thus, we initially postulated GPSM1 in GCs might play an important role in apoptosis by regulating the activation of cAMP pathways.

To verify this hypothesis, we first demonstrated the silencing of Gpsm1 induced GC apoptosis and inhibited proliferation. Furthermore, it was confirmed that the generation of cAMP was correlated to the expression of GPSM1 in rat GCs. Next, we explored the downstream signaling molecules of cAMP in GCs. There was no decline in PKA levels, but PKAc decreased when GPSM1 was down-regulated, which suggested the subsequent signal transduction mediated by cAMP might not be transmitted by the change of PKA level, but probably by the level of PKAc, which is an active subunit decomposed from PKA. Concomitant with the reduction of PKAc, CREB, a target molecule of PKA, as well as an important mediator of multiple signal transduction pathways in GCs $[27,28]$, was found to be less phosphorylated in Gpsm1knockdown cells. Bcl-2 is a well-known target of CREB [12], and was also reported as one of the important apoptosis suppressors in GCs [29]. Bax-dependent apoptosis is a common pathway of cell death and the balance of Bcl-2 and $B a x$ is a key determinant of the survival or death of GCs. As expected, the level of $\mathrm{Bcl}-2$ and the ratio of $\mathrm{Bcl}-2 /$ Bax were found to be markedly reduced after downregulation of GPSM1. Finally, as apoptosis markers, Caspase-3 and cleaved Capase- 3 showed an uptrend in Gpsm1-knockdown cells.

\section{Conclusions}

In summary, we first identified GPSM1 as a susceptibility gene for POI, and found it to be associated with follicular development in rats. Then, we confirmed the anti-apoptotic and proliferative functions of GPSM1 in rat GCs, and found that the possible mechanism of action might be through regulation of the $\mathrm{Bcl}-2 / \mathrm{Bax}$ ratio through cAMP-PKA-CREB signaling, which affects the activation of apoptosis protein, Caspase-3, ultimately 
A
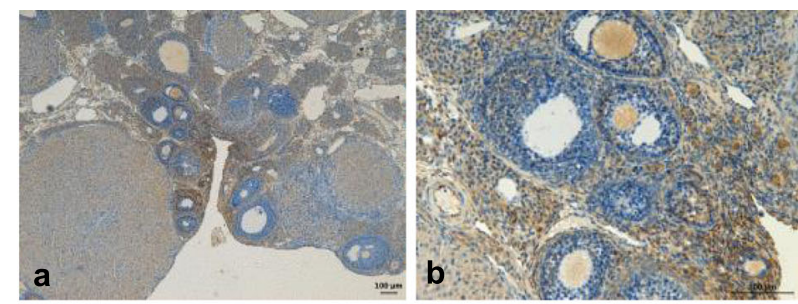

C

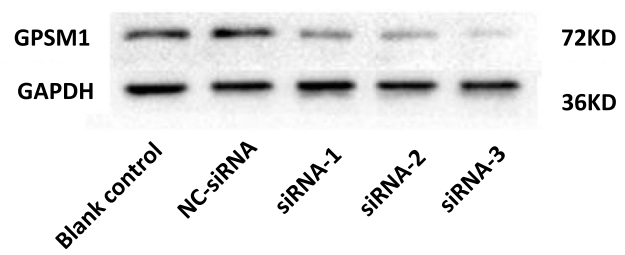

E

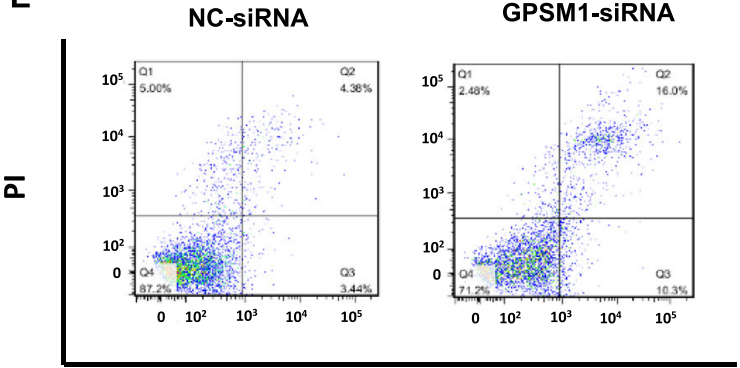

Annexin V-FITC
B

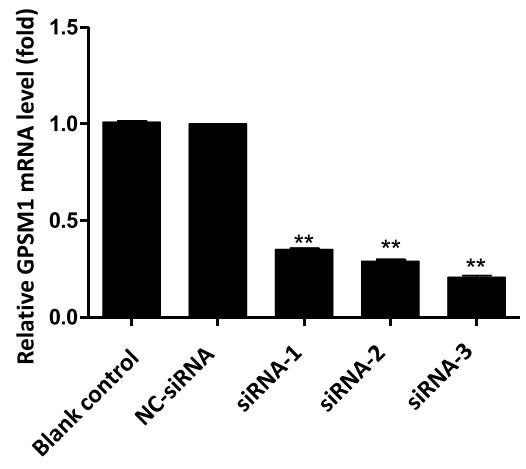

D

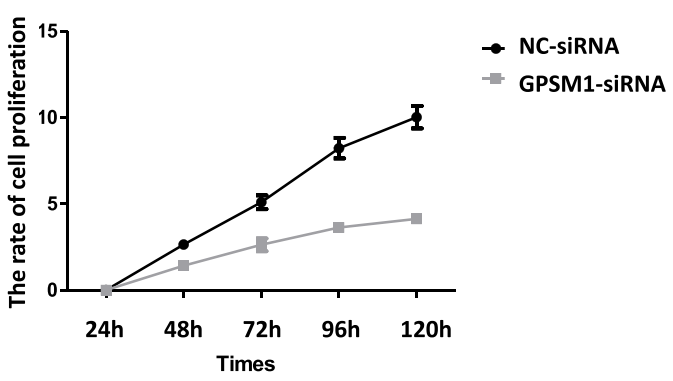

F

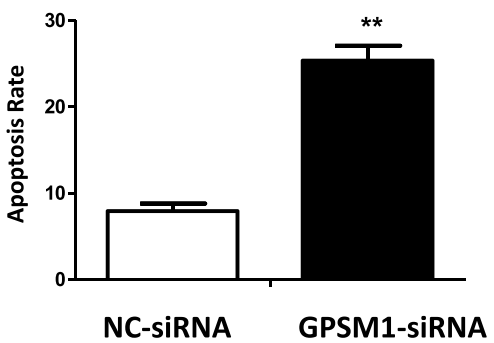

Fig. 3 The effect of silencing GPSM1 on GCs. A. The expression of GPSM1 in rat ovaries detected by immunohistochemistry. B and C. Silencing of Gpsm1 expression in GCs using siRNAs. RT-PCR (B) and western blot (C) analyses showed that Gpsm1-targeting siRNA-3 provided optimal depletion of GPSM1 in GCs compared to the siRNA-negative control (NC-siRNA) and blank control $\left(^{* *} P<0.01\right)$. D. Gpsm1-knockdown decreased the proliferation rate of GCs significantly $48 \mathrm{~h}, 72 \mathrm{~h}, 96 \mathrm{~h}$, and $120 \mathrm{~h}$ after transfection with siRNA. GCs transfected with NC-siRNA or Gpsm 1-siRNA were subjected to CCK8 analysis ( $\left({ }^{* *} P<0.01\right)$. E and F. Gpsm 1-knockdown increased the apoptosis rate of GCs. GCs transfected with NC-siRNA or Gpsm1-siRNA were subjected to Annexin V-FITC/PI double staining and flow cytometric analysis ( $\left.{ }^{* *} P<0.01\right)$

determining the survival or death of GCs. While further studies are required to verify the results of this study, our findings shed light on the etiology of POI by providing new candidates and pathways to explore.

\section{Methods}

\section{Ethics statement and patients}

This study was approved by and performed in accordance with the Ethics Committee of ZhuJiang Hospital of the Southern Medical University. All patients gave written informed consent for whole-exome sequencing.

A total of 20 unrelated Han Chinese women were recruited. All had at least 6 months of amenorrhea before the age of 40, high FSH plasma levels $(>25 \mathrm{IU} / \mathrm{mL})$ twice at least 4 weeks apart, and a normal 46 XX karyotype. Women having a background of pelvic surgery, anticancer treatment, ovarian infection, autoimmune disease, and/or positive family history were excluded from this study. The clinical characteristics of 20 POI patients are summarized in detail in Supplemental Table 1.

\section{WES and bioinformatics analysis}

Genomic DNA from patients was extracted from peripheral blood leukocytes using standard procedures. WES was performed on patients 1-10 using the SureSelect $\mathrm{Hu}$ man All Exon V6 /V6 + UTR Kit (Agilent Technologies, Santa Clara, CA, USA) on the NextSeq 500 platform from Illumina (San Diego, CA USA). The raw image files were 


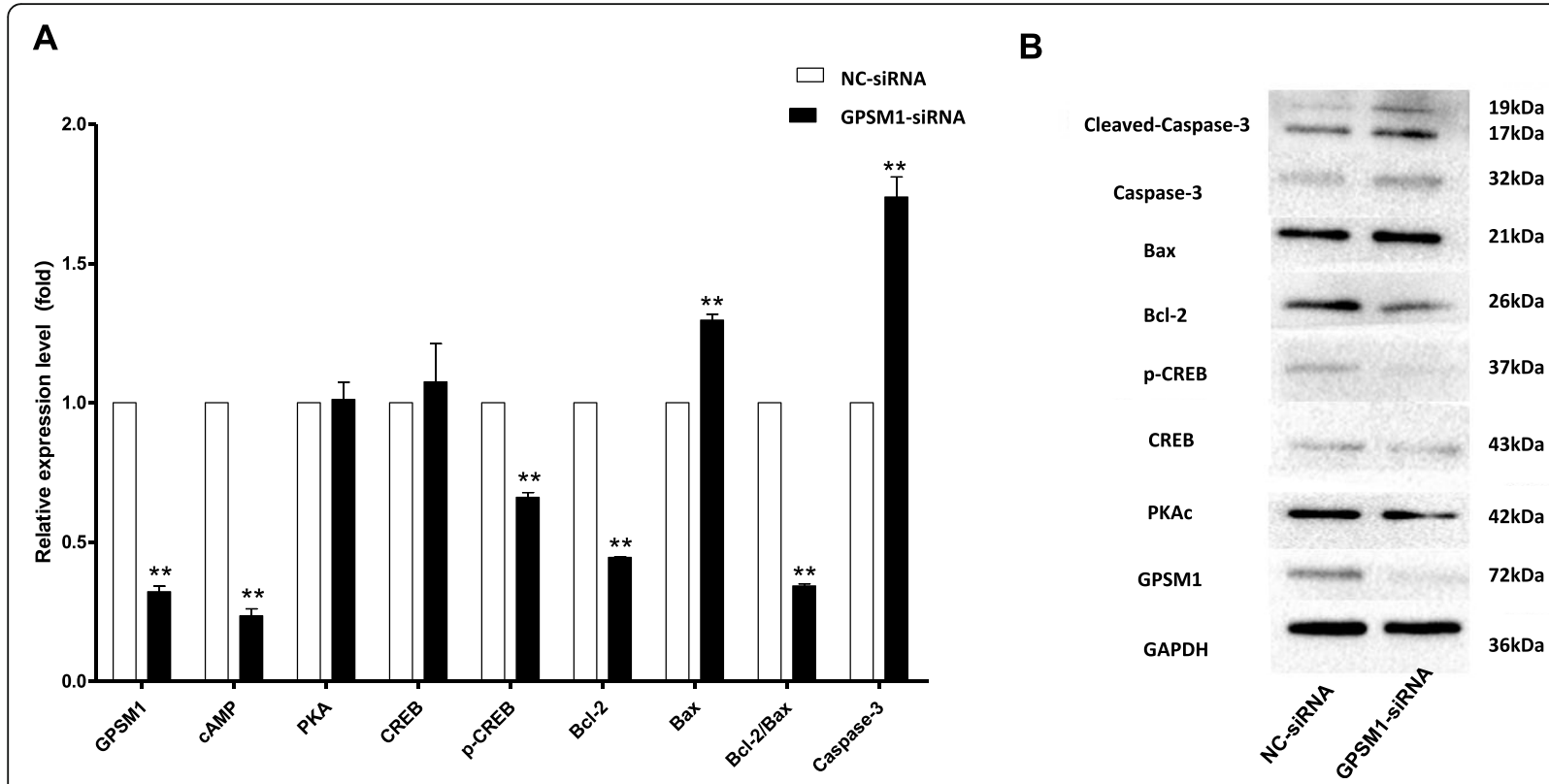

Fig. 4 Silencing of Gpsm1 alters the expression of the CAMP-CREB-PKA signaling molecules in GCs. After GCs were transfected with NC-siRNA and Gpsm1-siRNA, RT-PCR (a) and western blot (b) analyses were performed to measure the levels of GPSM1 and intracellular signaling molecules. The average results from three independent experiments are shown $\left({ }^{* *} P<0.01\right)$

processed into variants with high reliability through several steps of base calling, quality control, alignment, and calibration. Basic sequencing information, including bases, length of reads, depth, and coverage is available in Supplemental Table 2. Single nucleotide variants and indels were then annotated using ANNOVAR. Variants fulfilling the following criteria were retained: (1) absent or rare variants (frequency < 0.01) in the dbSNP, 1000 Genomes Project, and Exome Aggregation Consortium databases; (2) protein structure-altering variants with pathogenicity predicted by SIFT, PolyPhen2, Mutation Assessor, and Mutation Taster.

\section{Validation of mutation by sanger sequencing}

The mutations identified by WES and selected after literature reference were verified by Sanger sequencing in all 20 patients. Primers were designed to amplify the target region flanking the mutation site and are listed in Supplemental Table 3. Purified PCR products were sequenced on an ABI 3730XL (Applied Biosystems, USA) using the BigDye 3.1 Terminator Sequencing Kit (Applied Biosystems, USA) following the manufacturer's protocol.

Induction of follicle development and isolation of ovaries in rats

To stimulate follicular growth, immature female Sprague-Dawley (SD) Rats (24-25 days) were intraperitoneally injected with pregnant mare serum gonadotropin (PMSG, $40 \mathrm{IU} / \mathrm{rat}$ ) (Ningbo Second Hormone
Plant, Zhejiang, China). The experimental group (PMSG group, $n=3$ ) was treated as above. The control group (NS group, $n=3$ ) was intraperitoneally injected with an equal volume of normal saline (NS). Rats were sacrificed $48 \mathrm{~h}$ later, and the ovaries were removed immediately and cleaned with phosphate-buffered saline (PBS) for subsequent assays. One ovary of each rat $(n=6)$ was used for RT-PCR, and one for western blotting.

\section{Immunohistochemistry}

Ovaries of mature female SD rats (12 weeks) were removed, formalin fixed, paraffin embedded, sectioned $(4 \mu \mathrm{m})$, deparaffinized, and rehydrated. Endogenous peroxidase activity was blocked by incubation of the sections with $3 \% \mathrm{H}_{2} \mathrm{O}_{2}$ for 15 min. Nonspecific binding was blocked with $5 \%$ bovine serum albumin (CWBIO, Jiangsu, China) for $30 \mathrm{~min}$. After washing, sections were incubated overnight at $4{ }^{\circ} \mathrm{C}$ with an antibody against GPSM1 (1:200, Proteintech, Wuhan, China), followed by incubation with a biotinylated secondary antibody (1: 1000) for $1 \mathrm{~h}$ at room temperature. After washing, the antibody complexes were visualized with a DAB Kit (ZSGB-BIO, Shanghai, China) according to the manufacturer's instructions. The sections were counterstained with hematoxylin, then dehydrated, and mounted.

\section{Isolation and culture of primary rat GCs}

PMSG was intraperitoneally injected into immature female SD rats aged $24-25$ days at $40 \mathrm{IU} /$ rat. The rats were sacrificed $48 \mathrm{~h}$ later and the ovaries were immediately 
removed. After washing with PBS, the ovaries were placed in DMEM/F12 medium. GCs were released from the ovarian follicles into the medium by a syringe needle under an anatomic microscope, and then purified by filtration with a 200- $\mu \mathrm{m}$ stainless steel mesh. The isolated GCs were centrifugated at $1000 \times g$ for $5 \mathrm{~min}$ and then resuspended in medium. The GCs were seeded in 6-well plates $\left(1 \times 10^{6}\right.$ cells/well) and cultured in DMEM/F12 containing 1\% Penicillin/ Streptomycin and 15\% fetal bovine serum at 37 $\mathrm{C}$ with $5 \% \mathrm{CO}_{2}$ for $48 \mathrm{~h}$ to allow cells to attach.

\section{Transfection}

Synthetic small-interfering RNAs (siRNAs) were purchased from Sangon Biotech (Shanghai). The sequences of Gpsm1-siRNA were 5'-CCUGCGGCACCUUG UCAUUTT-3', 5'-GCCUAUGGCAACCUGGGUATT$3^{\prime}$, and 5' -CCGAUUCGAUGAGGCAAUUTT-3', named siRNA-1, siRNA-2, and siRNA-3, respectively. The sequence of siRNA for the negative control was 5 'UUCUCCGAACGUGUCACGUTT-3', named NCsiRNA. The siRNAs were delivered into the cells with Lipofectamine 3000 (Life Technology, Invitrogen, USA) according to the protocols supplied. The RNA and protein samples were collected $48 \mathrm{~h}$ and $72 \mathrm{~h}$ after transfection, respectively.

\section{RNA isolation and RT-PCR}

Total RNA was isolated from ovarian tissues or cultured GCs using TRizol reagent (TaKaRa, Japan) according to the manufacturer's instructions. The first-strand cDNA for total RNA was synthesized using PrimeScript ${ }^{\mathrm{nt}} \mathrm{RT}$ Reagent Kit with gDNA Eraser (TaKaRa, Japan). The expression levels of mRNA were detected by TB Green Premix Ex Taq II (TaKaRa, Japan) on a Bio-Rad Real-Time PCR system (Bio-Rad Inc., USA). Gapdh was used as the internal mRNA control. Target gene expression was determined using the $2^{-\Delta \Delta C t}$ method. The primer sequences for amplification are listed in Supplemental Table 4.

\section{Western blot analysis}

Total proteins were extracted from ovarian tissues or cultured GCs using RIPA Lysis Buffer (Beyotime Biotechnology, Shanghai, China) containing $1 \%$ phosphatase inhibitor and $1 \%$ protease inhibitor. The protein samples $(15 \mu \mathrm{g})$ were loaded onto the sodium dodecyl sulfate polyacrylamide gel for electrophoresis, and then transferred to polyvinylidene difluoride membranes (Merck Millipore, Germany). After blocking in 5\% non-fat milk at room temperature for $2 \mathrm{~h}$, primary antibodies against GAPDH (1:500, Proteintech, Wuhan, China), GPSM1 (1: 1000, Proteintech, Wuhan, China), PKAc (1:1000, Cell Signal, Beverly, MA, USA), CREB (1:1000, Cell Signal, Beverly, MA, USA), p-CREB (1:1000, Abcam, Cambridge, UK), Bcl-2 (1:1000, AbSci, WA, USA), Bax (1:
1000, Proteintech, Wuhan, China), Caspase-3 (1:1000, Cell Signal, Beverly, MA, USA), and cleaved caspase-3 (1:1000, Cell Signal, Beverly, MA, USA) were incubated at $4{ }^{\circ} \mathrm{C}$ overnight. The membranes were then incubated with secondary antibodies (1:500, Proteintech, Wuhan, China) for $1 \mathrm{~h}$ at room temperature. ECL detection reagent (Merck Millipore, Billerica, MA, USA) was used to visualize the bands. All experiments were repeated at least 3 separate times.

\section{Cell counting Kit-8 (CCK8) assay}

Transfected GCs $\left(2 \times 10^{3}\right)$ were plated into a 96-well plate. At 24, 48,72, 96, and $120 \mathrm{~h}$, cells were treated with $10 \mu \mathrm{L}$ CCK-8 solution (Corning, Beijing, China) per well. The absorbance value (OD value) of each well was measured at $450 \mathrm{~nm}$ on a microplate reader after incubation at $37^{\circ} \mathrm{C}$ for $2 \mathrm{~h}$. Each group was established in 5 wells. The proliferation rate was calculated and the cell proliferation curve was drawn. All tests were repeated at least 3 times.

Proliferation rate $(\%)=($ mean $\mathrm{OD}$ value at detection time point - OD value in blank group) / (mean 24 $\mathrm{h}$ OD value $-24 \mathrm{~h}$ OD value in blank group).

\section{Flow cytometry-based annexin/ propidium iodide (PI) assay}

GCs seeded in 6-well plates were transfected with siRNA and cultured for $48 \mathrm{~h}$. Then $1 \times 10^{6}$ cells were collected, washed twice with ice-cold PBS, and resuspended in binding buffer containing Annexin V-FITC and PI. After incubating for $30 \mathrm{~min}$ in the dark, cells were analyzed using a BD FACSVerser flow cytometer system (BD Biosciences, USA) equipped with BD FACSuite software.

\section{Statistical analysis}

All data were analyzed using SPSS software (Version 22.0, SPSS Inc., Chicago, USA), and the results are presented as mean \pm SEM using at least 3 independent experiments. An unpaired Student t-test was performed when comparing two groups and one-way ANOVA was performed when comparing more than two groups. A $P$ value of 0.05 or less was considered statistically significant $\left({ }^{*} P<0.05,{ }^{* *} P<0.01\right)$.

\section{Supplementary Information}

The online version contains supplementary material available at https://doi. org/10.1186/s13048-020-00740-6.

Additional file 1: Table S1. Basic clinical characteristics of POI patients. Table S2. Raw date of whole exon sequencing. Table S3. Primers for Sanger sequencing. Table S4. Primers for PCR.

\section{Abbreviations}

POI: Premature ovarian insufficiency; GPSM1: G protein signaling modulator 1; GCs: Granulosa cells; RT-PCR: Real Time-Polymerase Chain Reaction; 
CCK8: Cell counting kit 8; siRNA: Small interference RNA; WES: Whole-exome sequencing; FSH: Follicle-stimulating hormone; SNV: Single nucleotide variants; SD: Sprague-Dawley; PMSG: Pregnant mare serum gonadotropin; NS: Normal saline; PBS: Phosphate-buffered saline; AGS3: G protein signaling 3

\section{Acknowledgments}

We appreciated all patients for their participation.

\section{Authors' contributions}

Xuzi Cai and Xuefeng Wang conceived and designed the study. Xuzi Cai and Huijiao Fu performed the experiments. Yan Wang and Qiwen Liu analyzed and interpreted the patient data regarding POI. Xuzi Cai wrote the paper. Xuefeng Wang reviewed and edited the manuscript. All authors read and approved the manuscript.

\section{Funding}

This study was supported by the Science and Technology Planning Project of Guangdong province, China [2017A020214012] and Natural Science Foundation of Guangdong Province, China [2019A1515010452].

\section{Availability of data and materials}

The raw data of WES required to reproduce these findings cannot be shared at this time as the data also forms part of an ongoing study. Single nucleotide variants and indels were annotated using ANNOVAR (http://www. oponbioinformatics.org/annovar/). The variants were analysed using dbSNP (http://www.ncbi.nlm.nh.gov/snp/), 1000 Genomes Project (1000 g, http:// browser.1000genomes.org/index.html), and Exome Aggregation Consortium databases (ExAC, http://exac.broadinstitute.org/).

\section{Ethics approval and consent to participate}

The experimental protocol was established, according to the ethical guidelines of the Helsinki Declaration and was approved by the Human Ethics Committee of ZhuJiang Hospital of the Southern Medical University. Written informed consent was obtained from individual or guardian participants.

\section{Consent for publication}

Written informed consent for publication was obtained from all participant.

\section{Competing interests}

The authors declare that they have no competing interests.

Received: 24 March 2020 Accepted: 12 November 2020 Published online: 21 November 2020

\section{References}

1. European Society For Human Reproduction And Embryology ESHRE Guideline Group On POI, Webber L, Davies M, Anderson R, Bartlett J, Braat $D$, et al. ESHRE guideline: management of women with premature ovarian insufficiency. Hum Reprod (Oxford, England). 2016;31(5):926-37 https:// www.ncbi.nlm.nih.gov/pubmed/27008889.

2. Luborsky JL, Meyer P, Sowers MF, Gold EB, Santoro N. Premature menopause in a multi-ethnic population study of the menopause transition. Hum Reprod (Oxford, England). 2003;18(1):199-206.

3. Nelson LM. Primary ovarian insufficiency. New Engl J Med. 2009;360(6):60614 https://www.ncbi.nlm.nih.gov/pubmed/19196677.

4. Welt CK. Primary ovarian insufficiency: a more accurate term for premature ovarian failure. Clin Endocrinol. 2008;68(4):499-509 https://www.ncbi.nlm. nih.gov/pubmed/17970776.

5. Qin Y, Jiao X, Simpson JL, Chen ZJ. Genetics of primary ovarian insufficiency: new developments and opportunities. Hum Reprod Update. 2015;21(6):787808 https://www.ncbi.nlm.nih.gov/pubmed/26243799.

6. Carlosama C, Elzaiat M, Patiño LC, Mateus HE, Veitia RA, Laissue P. A homozygous donor splice-site mutation in the meiotic gene MSH4 causes primary ovarian insufficiency. Hum Mol Genet. 2017;26(16):3161-6 https://www.ncbi.nlm.nih.gov/pubmed/28541421.

7. Smirin-Yosef P, Zuckerman-Levin N, Tzur S, Granot Y, Cohen L, Sachsenweger J, et al. A Biallelic mutation in the homologous recombination repair gene SPIDR is associated with human gonadal Dysgenesis. J Clin Endocrinol Metab. 2017;102(2):681-8 https://www.ncbi. nlm.nih.gov/pubmed/27967308.
8. Caburet S, Arboleda VA, Llano E, Overbeek PA, Barbero JL, Oka K, et al. Mutant cohesin in premature ovarian failure. New Engl J Med. 2014;370: 943-9 https://www.ncbi.nlm.nih.gov/pubmed/24597867.

9. de Vries L, Behar DM, Smirin-Yosef P, Lagovsky I, Tzur S, Basel-Vanagaite L. Exome sequencing reveals SYCE1 mutation associated with autosomal recessive primary ovarian insufficiency. J Clin Endocrinol Metab. 2014;99(10): E2129-32 https://www.ncbi.nlm.nih.gov/pubmed/25062452.

10. Fonseca DJ, Patiño LC, Suárez YC, de Jesús Rodríguez $A$, Mateus $H E$, Jiménez KM, et al. Next generation sequencing in women affected by nonsyndromic premature ovarian failure displays new potential causative genes and mutations. Fertil Steril. 2015;104(1):154-62 https://www.ncbi.nlm. nih.gov/pubmed/25989972.

11. Wang W, Li Q, Zou F, Yu Z, Wang Y, Lu T, et al. Increased expression of AGS3 in rat brain cortex after traumatic brain injury. J Neurosci Res. 2013; 91(5):726-36 https://www.ncbi.nlm.nih.gov/pubmed/23404409.

12. Swart JM, Bergeron DM, Chiles TC. Identification of a membrane Ig-induced p38 mitogen-activated protein kinase module that regulates CAMP response element binding protein phosphorylation and transcriptional activation in CH31 B cell lymphomas. J Immunol. 2000;164:2311-9 https:// www.ncbi.nlm.nih.gov/pubmed/10679065.

13. Cismowski MJ, Takesono A, Ma C, Lizano JS, Xie X, Fuernkranz H, et al. Genetic screens in yeast to identify mammalian nonreceptor modulators of G-protein signaling. Nat Biotechnol. 1999;17(9):878-83 https://www.ncbi. nlm.nih.gov/pubmed/10471929.

14. Cismowski MJ, Takesono A, Bernard ML, Duzic E, Lanier SM. Receptorindependent activators of heterotrimeric G-proteins. Life Sci. 2001;68(19-20): 2301-8 https://www.ncbi.nlm.nih.gov/pubmed/11358340.

15. Blumer JB, Cismowski MJ, Sato M, Lanier SM. AGS proteins: receptorindependent activators of G-protein signaling. Trends Pharmacol Sci. 2005; 26(9):470-6 https://www.ncbi.nlm.nih.gov/pubmed/16084602.

16. Nadella R, Blumer JB, Jia G, Kwon M, Akbulut T, Qian F, et al. Activator of $G$ protein signaling 3 promotes epithelial cell proliferation in PKD. J Am Soc Nephrol. 2010;21 (8):1275-80 https://www.ncbi.nlm.nih.gov/pubmed/20488951.

17. Xing J, Lian M, Shen Q, Feng G, Huang D, Lu X, et al. AGS3 is involved in TNF-a medicated osteogenic differentiation of human dental pulp stem cells. Differentiation. 2015;89(5):128-36 https://www.ncbi.nlm.nih.gov/ pubmed/26143356.

18. Garcia-Marcos M, Ear J, Farquhar MG, Ghosh P. A GDI (AGS3) and a GEF (GIV) regulate autophagy by balancing $G$ protein activity and growth factor signals. Mol Biol Cell. 2011;22(5):673-86 https://www.ncbi.nlm.nih.gov/ pubmed/21209316.

19. Blumer JB, Smrcka AV, Lanier SM. Mechanistic pathways and biological roles for receptor-independent activators of G-protein signaling. Pharmacol Ther. 2007;113(3):488-506 https://www.ncbi.nlm.nih.gov/pubmed/17240454

20. Blumer JB, Lanier SM. Activators of $G$ protein signaling exhibit broad functionality and define a distinct core signaling triad. Mol Pharmacol. 2014; 85(3):388-96 https://www.ncbi.nlm.nih.gov/pubmed/24302560.

21. El-Nefiamy N, Abdel-Hakim K, Kanayama N. The selective prostaglandin EP4 agonist, APS-999 Na, induces follicular growth and maturation in the rat ovary. Eur J Endocrinol. 2005;152(2):315-23 https://www.ncbi.nlm.nih.gov/pubmed/15745941.

22. Ghersevich SA, Poutanen MH, Rajaniemi HJ, Vihko RK. Expression of 17 betahydroxysteroid dehydrogenase in the rat ovary during follicular development and luteinization induced with pregnant mare serum gonadotrophin and human chorionic gonadotrophin. J Endocrinol. 1994; 140(3):409-17 https://www.ncbi.nlm.nih.gov/pubmed/8182368.

23. Matsuda F, Inoue N, Manabe N, Ohkura S. Follicular growth and atresia in mammalian ovaries: regulation by survival and death of granulosa cells. J Reprod Dev. 2012;58(1):44-50 https://www.ncbi.nlm.nih.gov/pubmed/22450284.

24. Chabardès $D$, Imbert-Teboul M, Elalouf JM. Functional properties of Ca2+ -inhibitable type 5 and type 6 adenylyl cyclases and role of Ca2+ increase in the inhibition of intracellular cAMP content. Cell Signal. 1999;1 (9):651-63 https://www.ncbi.nlm.nih.gov/pubmed/15745941.

25. Jolly PD, Tisdall DJ, Heath DA, Lun S, Mcnatty KP. Apoptosis in bovine granulosa cells in relation to steroid synthesis, cyclic adenosine $3^{\prime}, 5^{\prime}-$ monophosphate response to follicle-stimulating hormone and luteinizing hormone, and follicular atresia. Biol Reprod. 1994;51(5):934-44 https://www. ncbi.nlm.nih.gov/pubmed/7849196.

26. Richards JS. Perspective: the ovarian follicle--a perspective in 2001. Endocrinology. 2001;142(6):2184-93 https:/www.ncbi.nlm.nih.gov/pubmed/11356661.

27. Fang $L$, Chang HM, Cheng JC, Leung PC, Sun YP. Nitric oxide and CGMP induce COX-2 expression and PGE2 production in human granulosa cells 
through CREB signaling pathway. J Clin Endocrinol Metab. 2015;100(2): E262-9 https://www.ncbi.nlm.nih.gov/pubmed/25423567.

28. Matulis CK, Mayo KE. The LIM domain protein FHL2 interacts with the NR5A family of nuclear receptors and CREB to activate the inhibin-a subunit gene in ovarian granulosa cells. Mol Endocrinol (Baltimore, Md). 2012;26(8):127890 https://www.ncbi.nlm.nih.gov/pubmed/227340361.

29. Depalo R, Nappi L, Loverro G, Bettocchi S, Caruso ML, Valentini AM, et al. Evidence of apoptosis in human primordial and primary follicles. Hum Reprod (Oxford, England). 2003;18(12):2678-82 https://www.ncbi.nlm.nih. gov/pubmed/14645191.

\section{Publisher's Note}

Springer Nature remains neutral with regard to jurisdictional claims in published maps and institutional affiliations.

Ready to submit your research? Choose BMC and benefit from:

- fast, convenient online submission

- thorough peer review by experienced researchers in your field

- rapid publication on acceptance

- support for research data, including large and complex data types

- gold Open Access which fosters wider collaboration and increased citations

- maximum visibility for your research: over $100 \mathrm{M}$ website views per year

At $\mathrm{BMC}$, research is always in progress.

Learn more biomedcentral.com/submissions 